Cadernos do IL $\odot$ Cadernos do IL $\odot$ Cadernos do IL $\odot$ Cadernos do IL e Cadernos do IL o Cadernos do IL

\title{
A LINGUÍSTICA COMO FAROL DAS CIÊNCIAS HUMANAS
}

\author{
Luis Felipe Rhoden Freitas*
}

\begin{abstract}
RESUMO: O objetivo deste artigo é explorar a metáfora de $S$. Bouquet de que, a partir da (re)descoberta de um Ferdinand de Saussure, o dito autêntico, a linguística poderia reivindicar seu papel de ciência guia. Será feita uma breve discussão da teoria saussuriana desde a publicação do Curso de Linguística Geral, de 1916, passando pelas possibilidades de leitura historicamente efetuadas do curso, até a publicação de seus escritos originais e de seus intérpretes atuais, sobretudo os mais notáveis, Claudine Normand e Simon Bouquet. Em consequência desse percurso de leituras feitas da obra de Saussure, serão discutidas algumas possíveis implicações da metáfora de Bouquet, a "linguística como farol das ciências humanas".
\end{abstract}

PALAVRAS-CHAVE: Saussure - linguística - curso

\begin{abstract}
The objective of this article is to discuss S. Bouquet's metaphor, which says that, from the "rebirth" of a so called authentic Ferdinand de Saussure, linguistics could claim the role of a leading science. At first, a brief discussion of Saussure's theory since the publication of Cours de Linguistique Gènèrale, from 1916, will take place, passing through the many reading possibilities that have been historically made, up to the publication of his original handwritings and his present readers, overall the most noticeable, Claudine Normand and Simon Bouquet. As a consequence of such reading path of Saussure's work, we propose to discuss some possible implications of Bouquet's metaphor, linguistics as a lighthouse to the human sciences.
\end{abstract}

KEYWORDS: Saussure - linguistics - course

\section{AS LEITURAS DE SAUSSURE}

Nada, possivelmente, é mais polissêmico do que a palavra "leitura". Começa por apresentar diferentes sentidos se vista da perspectiva lexical (como nas acepções de um dicionário, ou de abordagens linguísticas sobre o acontecimento da leitura para os sujeitos leitores), e ainda pode suscitar diferentes correlações entre leitor e objeto lido quando colocada num enunciado. Em "as leituras de Saussure", por exemplo, pode-se falar das leituras que Saussure fez, bem como das leituras que foram feitas de sua obra. No caso de Ferdinand de Saussure, há mais um agravante a compor a polissemia: a falta de unicidade sobre o Saussure que escreve.

A história já há muito conhecida é da sua não autoria de sua principal obra, o Curso de Linguística Geral, publicado em 1916. Elaborado por Charles Bally e Albert

* Professor do IFRS e mestrando do PPGLET/UFRGS em Teorias do Texto e do Discurso. Email: felipe_rhoden@hotmail.com. 
Secheaye, a partir de notas de alunos dos cursos de linguística que Saussure lecionou até falecer em 1913, o doravante CLG, ou simplesmente Curso, veio a um mesmo tempo fundar a linguística moderna e, de alguma forma controversa, "propor" o estruturalismo. Dezenas de anos mais tarde, com a publicação das obras manuscritas de Saussure, descobriu-se, entre tantas coisas, que Saussure propunha levar tão a fundo o questionamento sobre a "verdade da língua", que ele mesmo não fora capaz de encaixálo na ótica positivista de sua época, e muito menos tinha uma visão estruturalista da língua, se quisermos entender o termo de maneira reducionista. O resultado, se se pode dizer assim, é que os editores fizeram das suas ideias uma obra nos moldes positivistas, provavelmente para ser aceita nos meios acadêmico-científicos e da qual se fez, por muitos anos, uma leitura estruturalista. E nada disso teria sido a obra de Saussure, ou pelo menos não do "autêntico" Saussure, como reivindica o filósofo Simon Bouquet. Para este estudioso, Saussure não só não é o autor do CLG como também, argumenta ele, que os editores distorceram algumas de suas importantes ideias, o que será brevemente discutido adiante. Por isso que, ao se falar de Saussure, hoje em dia, é preciso sempre delimitar precisamente de qual Saussure se está falando.

$\mathrm{Na}$ conclusão "programática" de um artigo em que opõe o "verdadeiro" ao "pseudo" Saussure, Simon Bouquet sugere, a partir desta nova perspectiva saussuriana, que

Podemos até sustentar que a ciência da linguagem, encontrando sob a base desta epistemologia uma unidade que, hoje ela tem dificuldades para manter - rearticulando notadamente uma redução "cognitiva" e a perspectiva de ciência da cultura -, poderia reivindicar, sem falso pudor, um papel que nunca deixou de ser seu há dois milênios sob as diversas formas contingentes da sua cientificidade: o de "farol" das ciências humanas. (BOUQUET, 2009, $\mathrm{s} / \mathrm{p})$

Claudine Normand, sem discordar de Bouquet no que diz respeito à pluralidade saussuriana, mas também sem ratificar seu ponto de vista radical, inicia seu artigo de 2007 escrevendo que "de Saussure só podemos fazer leituras pessoais, o que supõe sempre interpretações, e, ao mesmo tempo, esquecimentos e reduções”. A partir dessa diretriz da estudiosa, várias questões surgem, como, por exemplo, quais leituras podemse fazer da obra Saussure? De qual Saussure se está falando, a cada vez que ele é citado, do Curso ou dos escritos autênticos? Esses diferentes Saussure ${ }^{1}$ são realmente tão opostos, diferentes, a ponto de podermos chamar-lhes antagônicos? E ainda, quais as implicações de se promover um cabo de guerra com a, aparentemente divisível, obra de duas "personas" do mesmo autor? A polêmica está lançada, mas não é nova nem requentada. Muito pelo contrário. A biografia do genebrino mostra que ele vivia esse

\footnotetext{
O uso do nome de Saussure antecedido por um determinante no plural pode ser encontrado na literatura e citamos dois exemplos. Um capítulo de História do Estruturalismo, de François Dosse, dedicado a Saussure (DOSSE, François. História do Estruturalismo: o campo do signo. Campinas: Editora da Unicamp, 1993,) e ainda, na forma interrogativa, no livro de Gadet \& Pêucheux (GADET, F. \& PÊUCHEUX, M. A língua inatingível: o discurso na história da linguística. Campinas: Pontes, 2004).
} 
dilema, do que talvez supunha vir a tornar-se polêmico: a redação de um manual-curso de linguística geral.

Temos, por um lado, o CLG, que é uma obra completa, no sentido acadêmicocientífico, com o objeto língua recortado da realidade da linguagem e dissecado, isto é, analisado a partir de suas "partes". Mas é uma obra que não é autêntica, não vem do punho do seu suposto autor. Nunca é demais lembrar, no entanto, que, apesar do acabamento positivista, o CLG possui questionamentos instigantes, questões por resolver; há nele um cerne dos dilemas saussurianos que os editores não conseguiram ou não quiseram excluir. Temos, por outro lado, os diversos escritos: os mesmos cadernos dos alunos em que se basearam os editores; os esparsos manuscritos de Saussure encontrados até $1996^{2}$ e os valiosos escritos para um curso de linguística que ele havia escrito, encontrados na residência da família naquele ano. Mas são, ao todo, escritos dispersos que tratam de diversos assuntos relacionáveis, que exigem dos seus analistas paciência e erudição, e que uma compilação e ordenação formando um objeto específico e bem recortado tornar-se-ia, talvez, tão pouco autêntico quanto o próprio CLG, e que por isso não dão a ninguém o direito de bater o martelo sobre o que dizia Saussure e o que queria Saussure com aquilo.

Parafraseando o personagem de W. Shakespeare, o príncipe Hamlet, pode-se afirmar, hoje, com pouca dúvida, que parece haver mais coisas na obra de Saussure, tanto do CLG quanto dos manuscritos, do que sonha a nossa vã filosofia da linguagem. Parece, inclusive, que mesmo essa possibilidade de diferentes leituras deste objeto que é a obra saussuriana e as dificuldades e polêmicas decorrentes dessa polissemia já estariam, de certa forma, previstas na máxima "o ponto de vista cria o objeto" do CLG. $\mathrm{Na}$ verdade, pode-se dizer que há, nas leituras apresentadas da obra de Saussure, disputa pela legitimação de diferentes pontos de vista. O interessante é que estes pontos de vista, mesmo se contraditórios, parecem não contradizer o fundamental das ideias de Saussure.

Nesse sentido, levando-se em conta o desenrolar histórico da obra e da repercussão da obra de Saussure, é sugerível que os grandes pontos de vista científicos podem ter influenciado ou mesmo ter sido influenciados pela chamada teoria linguística moderna. Era, no começo do século passado, a visão newtoniana-cartesiana que predominava nas então ciências exatas e naturais. Há algumas décadas, no entanto, a visão holística e a visão sistêmica dominam a física, sobretudo no seu subcampo, a física quântica, e têm influenciado, entre outras, a biologia, sobretudo na ecologia, e as ciências sociais ${ }^{3}$. E qual, não coincidentemente, é a orientação que se dá para a leitura mesmo do CLG, senão a que procura comprovar que a língua só pode ser descrita como um sistema em que as unidades estão em relação entre si?

Nas próximas seções trataremos, primeiramente, deste percurso de leituras da obra saussuriana, e depois da metáfora de Bouquet. Antes, porém, cabe anunciar o ponto

\footnotetext{
${ }^{2}$ Deram redação ao Escritos de Linguística Geral, (SAUSSURE, 2004) organizado por Simon Bouquet. Ver bibliografia.

${ }^{3}$ A obra do físico Fritoj Capra é um exemplo disso, o filme "Ponto de Mutação", popular na década de 1990, baseado em um livro seu, que tenta popularizar a Teoria dos Sistemas.
} 
Cadernos do IL e Cadernos do IL e Cadernos do IL e Cadernos do IL o Cadernos do IL o Cadernos do IL

de vista adotado para a trajetória de leituras. Trabant (2005) sugere três (ou quatro ${ }^{4}$ ) possibilidades de abordagens para a recepção da obra de e atribuída a Saussure, a saber: ou considerar somente o Curso, ou considerar somente os escritos autênticos, ou considerar o CLG como ponto de partida para se cotejá-lo com o conteúdo dos escritos autênticos. Por ser mais abrangente e, de certa forma, mais honesta com o desenrolar da teoria saussuriana historicamente, adotamos esta terceira perspectiva.

\section{O CURSO DE LINGUÍSTICA GERAL}

Nesse cenário em que se anuncia um "novo" ou "verdadeiro" Saussure, há também os que se propõem a fazer a releitura do CLG, não mais nos limites do estruturalismo, mas não sem deixar de reconhecer a influência positivista. Claudine Normand, pela defesa ostensiva que faz da obra, lidera essa equipe. Depois dela, Françoise Gadet (1996) faz um trabalho de leitura do Curso, inclusive, dando-se ao direito de questionar a ordem dos capítulos dada pelos editores sem, entretanto, mexer na sua redação. Seu livro Saussure: une science de la langue traz grandes trechos do curso comentados por ela. Ela argumenta que a ordem de apresentação das noções do CLG é problemática, como teria sido a Saussure. Seria melhor dispor das noções em uma ordem lógica? Ou em uma ordem cronológica? Uma contribuição de Gadet (1996, p. 63), entre outras igualmente importantes, foi observar que "nos capítulos da $2^{\mathrm{a}}$ e $3^{\mathrm{a}}$ partes do CLG estabelece-se a necessidade teórica do valor, mas é o capítulo 4 que efetivamente desenvolve esta noção". Pensa-se, com isso, em talvez se estudar o Curso começando pela noção de "valor", para, a partir dela, desenvolver as demais noções, como a de signo, de arbitrariedade, de sintagma e de paradigma, de diacronia e de sincronia, etc. ${ }^{5}$.

Segundo parece, o impacto da publicação no meio acadêmico do Cours de Linguistique Générale foi imediato à sua publicação. Ele trazia novos ares a um terreno da linguística já bastante viciado e sem renovação, o da Gramática Comparada. Curiosamente, Saussure mesmo era um comparatista. Ele questionava, no entanto, que "tal escola (...) não chegou a constituir a verdadeira ciência da Linguística. Jamais se preocupou em determinar a natureza de seu objeto" (CLG, p. 10). E pela empreitada ousada, ainda que controversa, de Bally e Secheahaye, publica-se o Cours.

Se quiséssemos resumir o conteúdo do CLG, sabendo o risco que se corre ao deixar-se algo importante de fora, ou fora de ordem, diríamos que, nele, discute-se qual seria o objeto da linguística, a língua vista a partir das regularidades. Isso é desenvolvido a partir da ideia de uma semiologia, que se trata de um sistema de signos. O signo, no Curso é, ao mesmo tempo, significante, a realidade material da língua, e

\footnotetext{
${ }^{4}$ A quarta possibilidade, a rigor, é a impossibilidade, que Trabant, de certa forma ironiza: fazer-se leitor ingênuo a ponto de poder ignorar de fato o CLG e o que deriva desta obra.

${ }^{5}$ A ideia, segundo nos parece, de se começar por compreender primeiramente a noção de valor, funciona se a tomamos como princípio geral que atravessa as demais noções. A ideia de conceitos primitivos, como se verá mais adiante, não torna a decisão de hierarquizar as noções nem um pouco mais fácil.
} 
significado, o conceito associado ao significante. A associação entre significante e significado é radicalmente arbitrária, ou "necessária", como depois se traduziu melhor a ideia $^{6}$. A língua é, então, composta de sintagmas, que são expressos linearmente no tempo e no espaço, e de paradigmas, formando uma espécie de terceira dimensão em que cada signo se relaciona com outros signos possíveis (o chamado eixo das associações). Nesse jogo entre signos, tanto pelos que estão postos na linearidade do sintagma quanto pelos que estão escolhidos pelo eixo associativo, em detrimento dos que são necessariamente excluídos, a toda e a cada peça do jogo é atribuída um valor ${ }^{7}$. Essa noção de semiologia da língua, a rigor, contrapõe-se à ideia de que a língua é uma nomenclatura porque postula que os sentidos estão em relação no sistema, isto é, opõese à noção clássica de que as palavras descrevem com algum acerto - ou, melhor dizendo, fazem referência precisa a - os objetos da realidade.

A significação acontece com os elementos postos (e os necessariamente excluídos) no sistema. Há, senão, apenas referência à dita realidade objetiva, e essa relação não é de um para um (cada objeto da realidade correspondendo a uma palavra ${ }^{8}$, e vice-versa). Há fatos da língua que não correspondem a nada na realidade objetiva, bem como há elementos da realidade que não têm seu equivalente na língua. Essa relação da significação com a dita realidade voltará a ser discutida na última seção.

Claudine Normand, em Saussure, aponta que o CLG, entre tantas outras coisas, separa a línguística da abordagem filosófica socrática (língua-nomenclatura), devido ao princípio da arbitrariedade do signo linguístico.

\begin{abstract}
Aplicar de maneira consequente o princípio do arbitrário é afastar, na descrição, qualquer outro ponto de vista diretor, e, em primeiro lugar, o do signo como representante de uma ideia. Dizer que na língua lidamos com a ligação mínima entre significantes e significados deve impedir toda tentativa de analisar a significação separando ideias e formas, como se estas servissem apenas como moldes mais ou menos adequados ou de reflexos mais ou menos fieis dessas primeiras. Por essa via, a linguística separa-se radicalmente de qualquer filosofia da linguagem. (NORMAND, 2009 p. 69)
\end{abstract}

Entretanto, como se pode ler em outras passagens, não há exatamente uma exclusão de qualquer concepção filosófica da língua e da linguagem, mas uma separação de conceitos bem distintos. A exclusão à filosofia se limita, talvez, ao que ela chama de "especulação filosófica", método analítico-dedutivo da filosofia clássica. Enquanto Saussure (aqui entendido como CLG, no próprio dizer de C. Normand) propunha-se a delimitar seu objeto e sua ciência, e para tanto debatia-se entre o que

\footnotetext{
6 "o signo, elemento primordial do sistema linguístico, encerra um significante e um significado cuja ligação deve ser reconhecida como necessária, sendo esses dois elementos consubstanciais um com o outro" (BENVENISTE, 2005 pg. 59)

${ }^{7}$ Associados à noção de valor concorrem a noção de identidade e a própria noção de significação. De acordo com Gadet (1996), "valor é uma potencialidade da língua e a significação é uma realização da fala (p. 66), que corrobora com a ideia de sistema.

${ }^{8}$ Nem tampouco "palavra" corresponde à unidade da língua.

9 NORMAND. Claudine. Saussure. São Paulo: Estação Liberdade, 2009.
} 
Cadernos do IL o Cadernos do IL o Cadernos do IL o Cadernos do IL o Cadernos do IL o Cadernos do IL

podia ser abstrato e concreto, postulava, dentro de um raciocínio puramente abstrato e também especulativo, os elementos puramente "concretos" da linguística.

O que fica não dito nesses enunciados é a necessidade de abstração; a ideologia científica da época, que limitava ao dado diretamente observável o domínio do pesquisador e não via na abstração senão a especulação filosófica, opunha-se às formulações explicitamente abstratas. (NORMAND, 2009, p. 59)

Cabe aqui, para que se entenda o argumento do parágrafo anterior, conceituar os usos de "especulativo", "abstrato" e "concreto"; e também o que é "filosófico". O especulativo em Saussure é, talvez, oposto ao método especulativo lógico-dedutivo da filosofia clássica, que fazia, de proposições em proposições silogísticas, chegar-se a uma conclusão. Como princípio de língua, os clássicos lançavam mão de uma noção de "substância" das coisas, dos objetos do mundo, que os "substantivos", portanto o léxico da língua, registravam ou representavam. Isto é, a própria ideia de referente, excluída da linguística saussuriana. $\mathrm{O}$ aforismo que talvez melhor sustenta a oposição à ideia de substância, no CLG, está na página 141: a língua é uma forma, não uma substância.

O que existe de especulativo em Saussure se assemelha a uma noção de coisa abstrata, do que não se pode apreender, digamos, fisicamente. A questão aqui implica colocar, de um lado, a ideia de língua como o que apreende a "substância" dos objetos no mundo (a alma das coisas...) e, de outro lado, a língua enquanto um sistema de signos que é, em si, abstrato, mas que, por referir aos objetos do mundo, constrói sua significação. Isto posto, cabe nos perguntarmos em que porto podemos ancorar a linguística saussuriana, o signo, os valores, as identidades? Em uma noção física e material, portanto, concreta, nesse sentido? A dificuldade aqui ainda é a mesma de sempre - tentar-se atribuir, para fins de explicação didática, uma natureza única, ou material ou pensamento puro, quando, na verdade, a língua tem a propriedade de abarcar ambas as realidades (digamos, por enquanto, fônica e conceitual). Mas disto, com justiça admitimos, já nos falava o CLG. A natureza da língua é dessa complexidade. Por isso que se pode questionar, mesmo dentro do próprio Curso, o uso dos termos abstrato e concreto e problematizá-los como exercício de leitura e interpretação do leitor de hoje em dia.

No texto do CLG, expressa-se a necessidade de se fazer objeção ao abstracionismo e à especulação filosófica. Isto provavelmente só se deve à tentativa de atribuir à linguística um caráter científico nos próprios moldes do positivismo, isto é, regido por leis gerais e dispondo de objetos concretos observáveis, "visíveis", como a própria Claudine Normand sugere:

É, em todo caso, a primeira vez que, sob o modelo da ciência social chamada por Comte a se constituir como uma física - a pesquisa sobre a linguagem e as línguas tenta pensar rigorosamente as propriedades de seu objeto e os limites do seu campo. Esse empreendimento é antes positivista, se dermos a esse termo todo o seu alcance epistemológico; mas se por esse programa ele se aproxima do horizonte filosófico de seu tempo, por seu 
Cadernos do IL o Cadernos do IL e Cadernos do IL o Cadernos do IL e Cadernos do IL o Cadernos do IL

caráter inacabado ele marca os limites do que pretende ultrapassar. (NORMAND, 2009, p. 83)

Ainda falando de oposições, é ponto pacífico que Saussure se opõe aos filósofos lógicos e propõe, talvez mesmo sem estar consciente disso, um corte epistemológico e sua consequente delimitação de objeto, o que em termos científicos teria um caráter "concreto". Mas isso tem como consequência, justamente, uma tomada de posição teórica e metodológica, que aqui pode ser entendida como uma filosofia da ciência. Veja-se a seguir a ambiguidade do termo filosofia:

\begin{abstract}
Saussure retira da linguística um problema permanente dos filósofos e, com certa arrogância, reduz suas teorias à da "língua-nomenclatura", concepção simplista de "certas pessoas". Essa exclusão do que se chamava ainda de "referente" e seu corolário (a língua é uma forma) eram essenciais para a definição do objeto e do campo. A formulação disso, no entanto, aparece tarde no Curso; ela obriga a uma tomada de posição em filosofia, ao mesmo tempo que esta nada tinha a dizer sobre a língua. (ibid, p. 89)
\end{abstract}

Na citação acima, filosofia pode ter dois sentidos antagônicos; o que Claudine aceita e o que ela rejeita. A primeira é relacionável à ideia de teorização; deriva da tentativa de um recorte epistemológico e pode ter como consequência uma proposta de elaboração de uma metodologia. A segunda é a lógico-socrática clássica, que não se ocupou da realidade da língua, mas a subordinou a ser coisa que descreve ora as coisas do pensamento, ora as coisas do mundo.

Mas voltando a questão sobre o abstrato e o concreto no CLG, o problema persiste. Lançando mão de uma tentativa, talvez ousada, de fazer semântica ao modo do Curso, diríamos que, em Saussure, os termos abstrato e concreto estão em uma espécie de antonímia motivada, um em relação ao outro. Além disso, tais adjetivos, na sua redação em 1916, estão no eixo das associações com a terminologia dos postulados da ciência positivista que tinha despontado, e não deveriam ser lidos somente com os olhos de hoje. Assim, abstrato e concreto parecem se opor, não só entre si, mas também aos seus sentidos atuais. Não estamos dizendo como se deve lê-los, mas, pelo contrário, sugerindo como se deve ter cautela ao se tentar interpretá-los com a visão de mundo de hoje.

Para se compreender a teoria do CLG, é necessário, como é dito hoje pelas ciências do conhecimento e da aprendizagem, fazer abstração para se poder elaborar conceitos. Se fosse diferente, bastar-nos-ia ter em um laboratório de linguística alguma espécie de cápsula onde se pudesse isolar a língua (do meio?) e observá-la em sua realidade física concreta. A teoria que vai explicar a língua não cabe em cápsulas. A mesma dificuldade que a metalinguagem impõe à linguística é também sua redenção, seu reduto de poder: a língua só se pode explicar nela mesma. E, para tanto, vai nos impor sua complexa realidade de ser, ao mesmo tempo, significante e significado, dimensões que só se verificam como prováveis unidades distintas na teoria, pois não se pode isolá-los um do outro. Nem para se explicar a si mesma, pois a língua tem uma 
dimensão concreta e uma abstrata que são indivisíveis (dado que leva Saussure a reivindicar, dentro da semiologia geral, uma semiologia específica para a língua). Por isso que entendemos a teoria saussureana como abstrata, mesmo no sentido especulativo e filosófico, isto é, de dimensão teórica, sem, com isso, contradizer Saussure. Ou, nos termos de Claudine Normand, passa a admitir que "Saussure, que não podia recorrer ao termo moderno "epistemologia", evocava, no âmbito particular, a respeito desse livro que ele hesitava em escrever, sua "linguística filosófica" (NORMAND, 2009, p. 107).

Resumindo o raciocínio feito até aqui, vejamos o seguinte. Em um primeiro momento, Normand exclui a filosofia do Curso. Refinamos os conceitos, cotejando partes do texto entre si, e vimos que o que ela exclui é a noção de referente, dentro de uma dada concepção filosófica, especulativa, da linguagem. Sobra uma concepção de filosofia (teórica). Da mesma forma questionamos o uso dos termos abstrato e concreto, não em Normand, mas no próprio CLG. Associamos o concreto ao intento positivista, como teria feito Saussure, e excluímos o abstrato por estar associado ao filosóficoespeculativo. Depois dessa exclusão, convertemos o sentido de "abstrato" a algo associado com a noção de conceito, que é parte do signo saussureano, e que só vai se opor à noção algo mais "concreta" da imagem acústica, mas que dela não se separa. Finalmente, sugerimos que a abordagem da linguística geral saussureana é, de fato, filosófica e abstrata, mas não com os sentidos que foram excluídos. É abstrata porque só se pode dizê-la na própria língua, e filosófica no sentido de ser uma teoria sobre o saber humano, que envolve a noção de língua como um sistema de signos, e cuja significação se constrói dentro do próprio sistema, com evidentes referências ao pensamento e ao mundo objetivo.

\section{AS FONTES MANUSCRITAS}

Simon Bouquet é radicalmente contra o Curso de Linguística Geral e não poupa desaforos tanto à obra quanto aos editores. Há, segundo o autor, dois paradigmas editoriais que são, como ele mesmo os designa, de o "pseudo-saussure" e o "Saussure autêntico". Ao primeiro paradigma, está associada ao CLG a ideia de obra apócrifa. No segundo paradigma estão as fontes manuscritas, as notas, os Escritos de Linguística Geral, editado por ele mesmo ${ }^{10}$, e mesmo as cartas dos que criticaram a ousada empreitada de Bally e Sechehaye, inclusive a de Albert Riedlinger, então aluno do curso de Saussure, cujo caderno teve uma participação fundamental na confecção do CLG.

Nesta sua empreitada contra o "pseudo-saussure", Bouquet escreve um artigo com o qual pretende dividir a história autoral de Saussure no meio, artigo que se chama "De um pseudo-saussure aos textos saussurianos originais". Nos parágrafos a seguir vamos retomar as principais críticas ao CLG dos editores. Ele aponta, por exemplo, que

\footnotetext{
${ }^{10}$ Aqui retomamos uma questão. Longe de ser uma edição em que houve uma nova redação de um texto, como foi o caso do CLG, o ELG não deixa, por outro lado, de ser uma seleção e uma compilação, além de ter sofrido algumas pequenas (ou grandes intervenções, sobre rasuras e outros tipos de hesitações), que já não são da própria mão de Saussure.
} 
Saussure não teria excluído a "linguística da fala" (ou do discurso), como faz parecer o CLG, onde está dito que "será, porém, necessário não confundi-la [a linguística da fala] com a Linguística propriamente dita, aquela cujo único objeto é a língua" (SAUSSURE, 1975, p. 28). A esse respeito, Bouquet ressalta que,

\begin{abstract}
de fato, a famosa frase final do Curso - "a linguística tem por único e objeto a língua considerada em si mesma e por si mesma" -, não corresponde a nenhum enunciado de Saussure, nem em suas aulas, nem em seus escritos. (...) Saussure afirma, de fato, que a linguística na qual ele concebe o programa é, sem si mesma, de dupla essência: linguística da língua e linguística da fala (ou do discurso). (BOUQUET, 2009, s/p)
\end{abstract}

E assim, desde uma tese central, a qual teria ocorrido aos editores a necessidade de se excluir, para fins de encaixe epistemológico, supomos, a linguística da fala, ou seja, as irregularidades de um dado objeto, toda a construção teórica de Saussure, segundo Bouquet, deveria ser revista. O filósofo observa, por exemplo, que a contribuição de Saussure ao introduzir os termos significante e significado, vai além do que os editores puderam depreender da ideia para a redação do Capítulo I da primeira parte. Os trechos abaixo, de seu artigo, testemunham que, para Bouquet, Bally e Secheahaye sobrepuseram sua tese à de Saussure:

Ele [Saussure] introduz a dualidade significante/significado para substituir a designação intuitiva signo/sentido que comumente utilizara até então, ele esclarece que não se trata apenas de um artefato terminológico destinado a readequar uma acepção "integral” da palavra signo. (...) Essa necessidade de não pensar as duas "faces" do signo separadamente retoma uma desontologização, esta vez não mais só por supressão do 'referente', mas por supressão dos objetos conceituais em si designados por significante e significado. In fine, o significado não é um valor do significante nem o significante um valor do significado (...) o signo bifacial é um valor em si". (...) "os pretensos editores não estavam atentos à ambiguidade da palavra signo, pela qual Saussure evoca tanto a entidade bifacial quanto a face única significante e, assim, não são coerentes com a escolha terminológica (signo, significante, significado) que eles reivindicam e aplicam em toda parte: de fato, nestes 9 casos eles mantêm o termo signo remetendo-se à entidade global no contexto do livro, enquanto que nas anotações dos estudantes (que acompanharam as aulas de Saussure), a ocorrência deste termo, anterior à introdução da designação tripla signo/significante/significado, denota claramente somente o significante. (BOUQUET, 2009, s/p)

Segue Bouquet dizendo que as outras sete passagens do Curso que tematizam o arbitrário do signo foram literalmente criadas, em seus detalhes, por Bally e Sechehaye, e para dizer isso, baseia-se no fato de que nenhuma sentença correspondente aparece nos textos fonte. Nestas sete passagens, diz ele, "o conceito de 'arbitrário do signo' $v i s$-à-vis do significado - aparece, no contexto, como uma criação de Bally e Sechehaye e assim, sempre no contexto, como um conceito significativamente opaco" (BOUQUET, 2009, s/p). E a seguir:

Cadernos do IL. Porto Alegre, n. ${ }^{\circ}$ 42, junho de 2011. p. 95-107. 


\begin{abstract}
Ora, isso revela que o conceito de 'arbitrário' referente a uma propriedade global e racional do signo (o arbitrário sistemático do signo) é certamente um conceito saussuriano e que não há nada de opaco nele. (...) A ironia do destino não para por aí... (...) Estas peripécias editoriais - que nos esclarecem sobre a má-compreensão dos "editores" - não teriam sido suficientes para barrar a recepção da concepção saussuriana do arbitrário sistemático, do qual a teoria do valor dá conta de fato. Todavia, como vamos ver, a própria teoria do valor não está menos gravemente deformada no Curso.
\end{abstract}

Bouquet é bem enfático ao dizer que a "deformação do conceito de 'valor' no Curso se deve, antes de tudo, ao fato de que no capítulo IV da II parte, cujo título anuncia genericamente $O$ valor lingüistico, não trata senão do valor in absentia". Por outro lado, nos textos originais "o termo valor designa precisamente uma pluralidade de fatos interdependentes: 1. valor in absentia interno (procedente do arbitrário interno do signo); 2. valor in absentia sistemático (procedente do arbitrário sistemático do signo); 3. valor in praesentia (procedente da sintagmatização do signo)". O problema gerado a partir dessa deformação é que o capítulo IV, no CLG, não dá definição global do conceito de valor. Essa questão é crucial, tanto para Bouquet como para o Saussure autêntico, talvez, por que a noção de sistema cujos elementos estão em relação é uma espécie de espinha dorsal epistemológica que dará sustentação às ciências humanas - a noção dos conceitos primitivos (retomada por Bouquet no ELG, como veremos brevemente a seguir). No artigo, ainda, Bouquet diz, sobre essa questão do valor, que "as anotações dos alunos atestam parte da sua complexidade numa caracterização muito clara" (BOUQUET, 2009, s/p):

\footnotetext{
O valor de uma palavra não se dá senão com relação às outras unidades semelhantes. A relação e a diferença das palavras entre si se desenvolvem seguindo duas ordens, em duas esferas completamente distintas: cada uma destas esferas será geradora duma certa ordem de valor e mesmo a oposição que há entre as duas esferas torna mais clara cada uma delas. Trata-se de duas esferas ou duas maneiras de coordenar as palavras, umas com as outras (...):

1. a coordenação sintagmática e a esfera das relações sintagmáticas (.) [i.e. as relações in praesentia];

2. a coordenação associativa (.) [i.e. as relações in absentia].” (BOUQUET, $2009, \mathrm{~s} / \mathrm{p})$
}

A sintaxe, entendida como a parte do Curso que Saussure não teve tempo de desenvolver, e que por isso teria ficado em aberto, é a questão assim formulada: "como a sintagmatização que ocorre na linearidade da fala pode ser considerada como um fato da língua?". Bouquet diz, a respeito disso, que Bally e Sechehaye "disponibilizarão uma representação bastante deformada das aulas: atulhando o texto com passagens que eles mesmos criaram sobre o valor in praesentia. Eles tomam a decisão de elucidar o problema deixado em aberto por Saussure". Ainda, diz o autor do artigo, que "contrariamente a apresentação confusa do Curso, as aulas do terceiro curso permitem 
Cadernos do IL 9 Cadernos do IL e Cadernos do IL e Cadernos do IL e Cadernos do IL o Cadernos do IL

subentender que a linguística da língua inclui a sintaxe" (BOUQUET, 2009, s/p).

Por fim, Simon Bouquet faz sua conclusão programática, propondo uma guinada: o banimento mesmo do CLG em detrimento das publicações do segundo paradigma. Diz ele:

\begin{abstract}
Se os textos saussurianos originais em quase nada influenciaram o destino da linguística no século XX, a descoberta dos manuscritos De l'essence double du langage e a publicação dos Écrits de Lingusitique Générale poderiam modificar este estado factual, evidenciando a necessidade de evitar todo amalgama entre o Pseudo-Saussure e o Saussure autêntico. Assim sendo, podemos esperar que os linguistas do século XXI, quando se debruçarem sobre os Écrits e as Leçons, descobrirão, além das divergências essenciais assinaladas mais acima os fundamentos de uma perspectiva epistemológica que faz falta aos estudos atuais. (ibidem)
\end{abstract}

Dificilmente conseguiríamos concordar com Bouquet integralmente na sua proposta radical. Por outro lado, algumas de suas contribuições são essenciais inclusive para elucidar, digamos, trechos do CLG que deixam perguntas, que apresentam algumas controvérsias. O que ainda podemos nos perguntar é, uma vez que o próprio Curso já teve um papel fundamental em suas relações teóricas e epistemológicas com as ciências humanas nos desenvolvimentos do estruturalismo, como isso teria se dado se, como Bouquet parece sugerir, o CLG não tivesse sido escrito, justamente, como o conhecemos?

\title{
A TEORIA DA SIGNIFICAÇÃO E SUAS PROVÁVEIS IMPLICAÇÕES NAS CIÊNCIAS HUMANAS
}

Primeiramente, a empreitada de se elaborar uma epistemologia disfarçada numa linguística (ou uma linguística disfarçada numa epistemologia?) já aponta para uma necessária reavaliação em uma certa abrangência de fazeres científicos. A linguística saussuriana é, dentre as ciências humanas, a que discute e problematiza, em primeira análise, o "instrumento" de abordagem e descrição (a língua) das outras ciências ${ }^{11}$. São duas coisas distintas. A língua é objeto de uma ciência específica, mas também é o "instrumento" de descrição dos objetos das demais ciências. As consequências disso são, para começar, uma vez que a língua não descreve exatamente a realidade, mas funciona significando-se a si e ao mundo descrito, desde que a partir do próprio sistema, não se pode mais falar ingenuamente em palavra, língua, texto, como representantes transparentes de qualquer objeto da realidade.

\footnotetext{
${ }^{11}$ A metáfora da língua como instrumento é sempre insuficiente. Mas quer se ressaltar, aqui, que enquanto para a linguística a língua é o objeto, ao mesmo tempo em que "instrumento" de abordagem desse objeto, para as outras ciências humanas, a língua, se considerada como transparente e despida de qualquer problematização, funciona como um mero instrumento. Para as ciências da linguagem, no entanto, a língua não é nunca somente um instrumento, mas um objeto complexo que pode ser abordado a partir de diversas perspectivas.
} 
Em Introdução à Leitura de Saussure, obra magistral de Bouquet, mas pouco acessível devido à complexidade e nível de informação, o autor perfaz um caminho do desenvolvimento das ciências para fazer localizar-se a linguística nesse percurso. Ele separa, num primeiro momento, as ciências entre saberes humanos positivos e não positivos $^{12}$. A diferença, resumidamente, é que um saber positivo pode ter seu objeto empiricamente percebido a posteriori, pois sua essência, ou seu valor de verdade, para usar um termo lógico, implica uma referência externa à linguagem: é um objeto no mundo, na realidade a ser descrito pela linguagem ou matematizado. $O$ saber não positivo, por outro lado, é composto de conceitos primitivos, isto é, interdependentes uns dos outros:

Em outras palavras, ainda, o saber não-positivo é um saber estruturado de tal maneira que o valor de verdade não implica um modo algum de referência externa direta. Sua única referência externa direta é a de não distinguível, a substância do real como um. É por essa razão que, literalmente - cada sistema filosófico, por exemplo, reconstrói o mundo. (BOUQUET, $2000 \mathrm{p}$. 29 , nota 8 )

Tendo Simon Bouquet localizado a linguística entre os saberes não positivos, aqueles cujos objetos não têm referência externa direta, e admitindo-se a exclusividade da linguística de ser ciência cujo objeto dela é ela mesma (isto é, é a ciência que faz referência à linguagem na própria linguagem), com todas as dificuldades que essa acarreta, também confere à linguística uma posição de destaque nas ciências de saberes não positivos. Isto, provavelmente, é o que quis dizer com "farol das ciências humanas". Pode-se dizer, ousadamente até, que mesmo as ciências dos saberes positivos, posto que em algum momento servem-se da língua, do discurso, para propor, para problematizar, para hipotetizar, para concluir, mesmo essas ciências teriam algo a lucrar com a incomodativa linguística.

As ciências que usam o discurso em algum ponto correm sempre o risco de ter uma visão ingênua sobre a linguagem (ou de não ter uma visão sobre a linguagem, que ainda assim é uma ignorância ingênua), supondo que a língua seja "transparente", mero meio para descrever a realidade exatamente. Nesse sentido, é a linguística que pode desfazer essa ingenuidade. Existe, por um lado, teorias sobre o discurso que admitem que o referente está sempre deslocado ou refratado, isto é, que a língua é opaca (em oposição a transparente), ou seja, seja qual for a metáfora que se use (o que, de certa forma, poderia ter sido a pioneira semântica saussuriana, tivesse ela sido desenvolvida).

É devido à questão da significação como é posta por Saussure, em sua bemelaborada (ainda que pouco entendida) teoria da significação que acontece a polissemia, o que faz parecer que um significante possa associar-se a diferentes significados. Mas estes sempre são, na verdade, outros signos, que possuem um sentido mais determinado

\footnotetext{
${ }^{12}$ Em primeira análise, essa distinção parece desfazer a confusão entre os conceitos concreto e abstrato para as ciências humanas, dificuldade terminológica que esteve presente no curso, como se discute a partir da leitura de Saussure (NORMAND, 2009).
} 
no seu próprio contexto de enunciação, isto é, possuem um valor in praesentia e in ausentia concomitantemente. A polissemia da palavra leitura, como aparece no começo do artigo, é a polissemia mesma da palavra palavra: tudo na língua é signo no jogo da significação, o que se atribui um valor, cuja arbitrariedade que junta significante e significado é necessária, que forma um sintagma em que concorrem paradigmas - um sistema que, para funcionar, depende de todos esses elementos funcionando concomitantemente, mas que ainda assim, pode ser descrito na teoria.

\section{REFERÊNCIAS}

BENVENISTE, Émile. A natureza do signo lingüístico. In: Problemas de

Linguística Geral I. Campinas: Pontes, 2005.

BOUQUET, Simon. De um pseudo-saussure aos textos saussurianos originais. Letras e Letras (Revista do Instituto de Letras e Linguística da Universidade Federal de Uberlândia). Volume 25. Número 1. jan/jun 2009. . Introdução à leitura de Saussure. São Paulo: Cultrix, 2000.

De MAURO, Tullio. Cours de linguistique générale. Édition critique préparée par Tullio de Mauro. Paris: Payot, 1972.

GADET, Françoise. Saussure: une science de la lange. Paris: PUF, 1996.

NORMAND, Claudine. Saussure: Une épistémologie de la linguistique. Atas de Colóquio, Séoul, 2007.

. Saussure. São Paulo: Estação Liberdade, 2009.

SAUSSURE, Ferdinand. Curso de Linguística Geral. São Paulo: Cultrix, 1975.

. Escritos da Linguística Geral (Organizados e editados por Simon Bouquet e Rudolf Engler). São Paulo: Cultrix, 2004.

TRABANT, Jürgen. Faut-il défendre Saussure contre ses amateurs? Notes item sur l'etymologie saussurienne. In: CHISS, Jean-Louis; DESSONS, Gérard. Langages, n. 159. Paris: Larousse, septembre 2005.

Cadernos do IL. Porto Alegre, n. ${ }^{\circ}$ 42, junho de 2011. p. 95-107. 